\title{
Research trends in the journal Hormones and Behavior (1987-2000)
}

\author{
A. Salvador,* M.A. Serrano, and E. González-Bono \\ Departamento de Psicobiologia y Psicologia Social, Facultad de Psicologia, Apartado 22109, Universidad de Valencia, 46071 Valencia, Spain
}

Received 24 July 2001; revised 22 August 2002; accepted 14 October 2002

\begin{abstract}
As a continuation of the study carried out by Svare more than 15 years ago (Horm. Behav. 22 (1988), 139) and to determine the tendencies of the evolution of behavioral endocrinology since then, our aim was to extend his work until 2000, assuming that the journal Hormones and Behavior would be representative of the field at large. To study this 14-year period and compare it with Svare's data, we kept the same criteria and categories, behavioral patterns, and species. Our results show that "sexual behavior" in "rodents" is still the most extensive field studied by behavioral endocrinologists, although frequency of other topics is increasing, above all "aggressive and emotional responses," and especially the interrelationships between them. Interestingly, studies dedicated to humans are slowly becoming more common. In addition to these analyses, we obtained the several citations received by a randomly selected sample of articles during the period that was divided by the number of years when the articles can be potentially cited. These ratios revealed that research on "humans," within the category of species, and on "memory, learning, and conditioning" and "aggressive and emotional responses," within the behavioral categories, present the highest visibility in the literature. Furthermore, this analysis was complemented with information about the main receptor journals of the papers published in Hormones and Behavior, classified by the same categories. All these data, although limited by the analysis of only one journal, permitted us to reflect on whether the evolution tendencies formulated by Beach (Horm. Behav. 15 (1981), 325) for this discipline were applicable to the period studied, thus confirming its status as a mature discipline for the last quarter of the 20th century.
\end{abstract}

(C) 2003 Elsevier Science (USA). All rights reserved.

Keywords: Behavioral endocrinology; Historical analysis; Bibliometry; Species; Behavioral patterns; Research trends; Citations

In 1988, Svare published a brief report in which he reviewed the article appearing in Hormones and Behavior from the beginning of its publication to 1986. According to the author, this was the journal that had been exclusively devoted to publishing research reports in behavioral endocrinology and, therefore, should be representative of the field at large (Svare, 1988, p. 139). He chose the same methodology employed almost 40 years before by Frank A. Beach in his outstanding paper, "The Snark was a Boojum" (Beach, 1950), that is, analyzing the behavioral pattern or system and the species studied in each article. Beach emphasized the dangerous situation that could arise when a

\footnotetext{
* Corresponding author. Área de Psicobiología, Facultad de Psicología, Apartado 22109, 46071 Valencia, Spain. Fax: +34-96-3864668.

E-mail address: Alicia.Salvador@uv.es (A. Salvador).
}

scientific field concentrated its attention excessively on a small number of species and a small number of behavioral patterns.

From his revision, Svare concluded that, clearly, the main focus in behavioral endocrinology continued to be "sexual behavior" in "rodents." A few years before, Gandelman (1984) had found similar results when he considered reports published in several journals during the period from 1975 through 1981. Journals considered in his study were Animal Behavior, Endocrinology, Hormones and Behavior, Journal of Comparative and Physiological Psychology, Journal of Endocrinology, Physiology and Behavior, and Science. He found $48 \%$ of the articles dedicated to reproductive behavior and $12 \%$ to aggression, compared to $38 \%$ dedicated to the rest of the behaviors. Furthermore, the choice of sexual behavior was even more pronounced for the two journals concerned more exclusively with endocrinological issues and only infrequently with behavior (En- 
docrinology and Journal of Endocrinology, with 80\% and $75 \%$, respectively). Gandelman concluded that the reliance upon a single type of dependent measure had its drawbacks because a large amount of existing data was specific to reproductive activity. Consequently, it was difficult to determine whether and to what extent the endocrine system exerted similar influences by way of similar mechanisms of action on behavior in general. He reviewed some historical, practical, and theoretical factors that had led to the ascendancy of reproductive activity as the behavior of choice for the study of hormonal influences on the expression of behavior.

The expansion experienced in behavioral endocrinology in the last few years makes one think of great changes and new tendencies in the development of this field. To verify these hypothetical lines of evolution, our aim was to continue his work until a potential, new historic date, 2000, which coincides with the end of the Decade of the Brain. To study this 14-year period and compare it with Svare's data, we used the same criteria and categories, behavioral patterns, and species. Based on Beach's methodology, behavioral patterns were classified into the following seven categories: (1) Sexual Behavior, (2) Aggressive and Emotional Responses, (3) Regulatory Behaviors (e.g., feeding, drinking, activity, and body weight regulation), (4) Memory, Learning, and Conditioning, (5) Social Communication (e.g., dominant/subordinate relationships, social hierarchies, scent marking, and ultrasonic and pheromone communication), (6) Sensation and Perception, and (7) Parental Care. Subjects were divided into the following four groups: (1) Rodents, (2) Nonrodent Mammals, (3) Birds, and (4) Reptiles, Amphibians, and Fishes. In some analyses, the Nonrodent Mammals category has been distributed into two subcategories, i.e., Nonrodent/Nonhuman Mammals and Humans, to provide more precise information. Moreover, articles have been classified as laboratory or field studies, to get a more complete image of the research trends.

Furthermore, the availability of citation indexes makes it possible to evaluate the visibility of the studies on ongoing research. In fact, by using these databases it is possible to determine whether the citation rates for the articles published in every category studied are decreasing or increasing. This strategy makes it possible, in addition to determining what the trends of research are in a particular research area, to know how their results are received. To complete that information, it is interesting to identify in which journals the articles published in Hormones and Behavior have the highest visibility, taking into account studies with different species and those investigating different behavioral categories. In summary, the present article aims to extend the analyses carried out by Svare on the distribution of publications in different subfields of behaviors and species and complete this information by analyzing their visibility by using citation analyses.

\section{Results}

During the period of our study (vol. 21 to 38), the journal Hormones and Behavior published one volume of four issues every year from 1986 up to and including 1996. Each issue contained from 7 to 13 articles. There were two exceptions that affect, in both cases, the last issue of each volume. In 1994, issue 4 included 28 works from the "U.S.Japan Steroids and Brain Symposium" (vol. 28). The fourth number from volume 30, published in 1996, was dedicated to a special issue, "Sexual Differences in Behavior," containing 32 articles. In both cases, there was also a note from the Editor, who in this period was Robert W. Goy together with R.K. Whalen. In the second issue of 1996, the formal announcement of the formation of the Society for Behavioral Neuroendocrinology (SBN) was published, Hormones and Behavior becoming "the official journal of this professional scientific society committed to understanding the interaction between behavior and neuroendocrine function" (vol. 30, pp 100-107).

In the first issue of 1997, Michael J. Baum, as new Editor, signed an editorial announcement, where he indicated his intention "to expand both the scope and the number of articles published each year, publishing research articles, reviews and special issues that represent the mainstream of contemporary experimentation and theory in the field of Behavioral Neuroendocrinology" (vol. 31, p. 1). From 1997 through 1999, two volumes containing three issues each were published yearly. In 2000, the two volumes were extended to include four issues, which contained between six and 12 regular articles per issue. Furthermore, two special issues appeared. In 1997, eight articles were added to regular articles within a special issue, "Single Gene Mutations, Gene Knockout, and Behavioral Neuroendocrinology" (vol. 31, no. 3). In 2000, 12 articles made up the total number dedicated to "Effects of Leptin and Related Hormones in the Control of Feeding and Energy Balance" (vol. 37, no. 4).

Of the 680 articles published in Hormones and Behavior from 1987 through 2000, only 568 were included in the analyses $(88.08 \%)$; the rest $(11.92 \%)$ were not used, following Svare's criterion of not including reviews, replies, and summaries of proceedings, as well as reports without behavioral variables. Of the 568 articles analyzed, $12.67 \%$ studied more than one behavior, which have been counted in each category (Table 1).

\section{Distribution of articles by species and behaviors studied}

Rodents were clearly the most frequently used species in Hormones and Behavior articles, although the number decreased across time (Table 1). Nonrodent Mammals was the following category, with important peaks. The other two categories presented a very similar percentage. Two articles that used insects and crustaceans could not be included in this classification. 
Table 1

Comparative data in the two periods studied

\begin{tabular}{lcc}
\hline & $1970-1986$ & $1987-2000$ \\
\hline Species & & \\
$\quad$ Rodents & $70 \%$ & $46 \%$ \\
Nonrodent Mammals & $12 \%$ & $22 \%$ \\
Birds & $9 \%$ & $16 \%$ \\
$\quad$ Reptiles, Amphibians, and Fishes & $8 \%$ & $15 \%$ \\
Behavioral patterns & & \\
Sexual Behavior & $54 \%$ & $44 \%$ \\
Social Communication & $14 \%$ & $14 \%$ \\
Aggressive and Emotional Responses & $11 \%$ & $16 \%$ \\
Parental Care & $7 \%$ & $10 \%$ \\
Regulatory Behaviors & $7 \%$ & $9 \%$ \\
Memory, Learning, and Conditioning & $5 \%$ & $5 \%$ \\
Sensation and Perception & $2 \%$ & $1 \%$ \\
Type of studies & & \\
Field studies & - & $12 \%$ \\
Laboratory studies & - & $88 \%$ \\
No. of total articles & 749 & 680 \\
Articles considered & $708(94 \%)$ & $568(83 \%)$ \\
Articles with several behaviors & $3 \%$ & $13 \%$ \\
Number of years considered & 17 & 14 \\
\hline
\end{tabular}

On the other hand, with regard to the behavioral patterns studied (Table 1), Sexual Behavior was still clearly predominant over the rest of the behaviors, with an important decrease in 1994 and 1995, as well as in more recent years. Aggressive and Emotional Responses was the following category in importance. Social Communication, Parental Care, and Regulatory Behaviors displayed intermediate percentages. Articles dedicated to Memory, Learning, and Conditioning showed a lower percentage, with a slight ascending tendency in the second part of the period studied. Sensation and Perception was the least studied topic.

When we compared data obtained by Svare and those of our study (see Table 1), Sexual Behavior continued to be the main behavior studied, although it decreased by a very important percentage, while Aggressive and Emotional Responses was higher than in the first period, becoming the category with the greatest increase. This category, next to Parental Care and Regulatory Behaviors, showed increases in comparison with the previous period studied by Svare (1970-1986). The rest of the categories (Social Communication; Memory, Learning, and Conditioning; and Sensation and Perception) suffered decreases, although in the latter case very little and probably without any important meaning.

It is worth noting that there was a great increment in the articles with data on several behaviors. Studying the combination of behavioral patterns, the following pairs appeared: sexual-aggression (15 articles), sexual-social behavior (10 articles), sexual-aggression-social behavior ( 9 articles), aggression-social behavior (7 articles). Between three and five articles studied the following combinations: regulatory-social behavior, aggression-parental behavior, sexual-parental behavior, sexual-regulatory behavior, sexual-parental behavior, and sexual-aggression-regulatory be- haviors. Only one or two articles studied other combinations.

As can be seen in Table 1, Rodents was the preferred sample of the authors that published in Hormones and Behavior, although there was a remarkable diminution in the second period. This decreased percentage benefited the other categories, which almost duplicated their representations. Humans were included within the Nonrodent Mammals. Specifically, there were 41 reports $(6.84 \%), 17$ on men, 18 on women, and 6 with mixed samples. These articles dealt with topics concerning sexual behavior, aggressive behavior/competition, menstrual cycle, maternal behavior, replacement hormonal therapy, anabolic steroids and personality, transsexualism and cognitive abilities, and adrenogenital syndrome. The evolution over the years was very irregular, with some years not producing any articles (1988, 1993, and 1994), although there was a continued representation in the following years, 1999 being the year that showed the greatest number (six articles).

Approximately $88 \%$ of the studies were carried out in the laboratory, while the rest were field studies. This distribution was fairly stable across time, with a light ascending tendency if the first half of the period studied was compared with the second half (30 compared to 38 articles). A still very small number of articles were dedicated to environmental issues in more recent years.

\section{Citation analyses}

To discover the visibility of the research published in this journal by means of citation analysis, $20 \%$ of the articles in each category were randomly selected for species and behavioral patterns, separately. The citations of these articles recorded in the Science Citation Index (SCI) and the Social Science Citation Index (SSCI) between 1987 and 2000 were identified. As the articles selected were published during the period studied, we aggregated the number of years that every articles included in a category could be potentially cited, starting from the year it was published until the end of the period considered. Afterward, the ratio of citations per year (number of citations/number of years) was computed for every category. This ratio was taken as a visibility index of the articles included in each category for the period studied. Results obtained are presented in Table 2. With regard to species, the highest visibility ratio was presented by Humans followed by Nonrodent/Nonhuman Mammals, with Birds obtaining the lowest ratio. Regarding behavioral patterns, the highest ratio was obtained by Memory, Learning, and Conditioning, followed at a distance by Aggressive and Emotional Responses. The lowest visibility ratio was for Social Communication.

Finally, we analyzed the journals that cited the articles in every category. The articles sampled dealing with the species considered received 1197 citations. Sixteen journals produced 596 citations, about $50 \%$ of the total. The journals that cited the most were Hormones and Behavior and Phys- 
Table 2

Data relative to articles selected for the analyses of citations

\begin{tabular}{lcccc}
\hline Category & $\begin{array}{l}\text { Articles } \\
\text { selected }\end{array}$ & $\begin{array}{l}\text { Aggregated } \\
\text { number of years } \\
\text { of potential } \\
\text { citation }\end{array}$ & $\begin{array}{l}\text { Citations } \\
\text { received }\end{array}$ & Citations/year \\
& & & & \\
Species & & 388 & 528 & 1.36 \\
Rodents & 53 & 108 & 230 & 2.13 \\
Nonrodents/Nonhuman Mammals & 15 & 43 & 108 & 2.51 \\
Humans & 8 & 141 & 141 & 1 \\
Birds & 19 & 139 & 190 & 1.37 \\
Reptiles, Amphibians, and Fishes & 18 & & 529 & 1.18 \\
Behaviors & 57 & 448 & 295 & 1.98 \\
Sexual Behavior & 20 & 149 & 85 & 1.02 \\
Aggressive and Emotional Responses & 13 & 83 & 147 & 4.74 \\
Regulatory Behaviors & 7 & 31 & 146 & 0.99 \\
Memory, Learning, Conditioning & 18 & 147 & 26 & 1.53 \\
Social Communication & 2 & 17 & 124 \\
Sensation and Perception & 14 & 99 & 1.25 \\
Parental Care & & & \\
\hline
\end{tabular}

iology and Behavior. In Table 3, the percentages of references provided by the most citing journals to the different species categories are presented. It is interesting to note that, among the five first citing journals, Hormones and Behavior concentrated citations on Reptiles, Amphibians, and Fishes; Physiology and Behavior on Nonrodent/Nonhuman Mammals; Behavioral Neuroscience and Brain Research on Birds; and Psychoneuroendocrinology concentrated heavily on Humans. Rodents showed the most ample distribution of percentages in many journals.

The articles selected referring to behavioral patterns received 1352 citations. The same journals considered above produced $51.19 \%$ of the citations (Table 4). Hormones and Behavior and Physiology and Behavior were also the most citing journals. Hormones and Behavior concentrated citations on articles dealing with Parental Care, while Physiology and Behavior mostly cited articles on Sensation and Perception. Brain Research and Behavioral Neuroscience cited many articles on Memory, Learning, and Conditioning and, finally, General and Comparative Endocrinology concentrated an important number of articles on Aggressive and Emotional Responses.

\section{Discussion}

To understand behavioral endocrinology more deeply, it is important to analyze its development over time (Salvador

Table 3

Percentage of citations per species for several journals

\begin{tabular}{|c|c|c|c|c|c|c|}
\hline & Rodents & $\begin{array}{l}\text { Nonrodent/nonhuman } \\
\text { mammals }\end{array}$ & Humans & $\begin{array}{l}\text { Reptiles, } \\
\text { amphibians, } \\
\text { and fishes }\end{array}$ & Birds & Other \\
\hline Horm. Behav. & 11.17 & 10.00 & 6.48 & 23.40 & 10.00 & 38.95 \\
\hline Physiol. Behav. & 14.39 & 12.17 & 5.56 & 2.84 & 4.74 & 60.3 \\
\hline Behav. Neurosci. & 4.17 & 2.61 & 2.78 & 2.84 & 4.21 & 83.39 \\
\hline Brain Res. & 3.79 & 2.61 & 0 & 2.84 & 5.26 & 85.5 \\
\hline Psychoneuroendocrinology & 2.08 & 6.09 & 8.33 & 0 & 1.05 & 82.45 \\
\hline J. Neuroendocrinol. & 3.79 & 1.74 & 0 & 2.84 & 3.68 & 87.95 \\
\hline Gen. Comp. Endocrinol. & 0.38 & 0 & 0 & 13.48 & 6.32 & 79.82 \\
\hline Neurosci. Biobehav. Rev. & 3.79 & 0.87 & 0 & 1.42 & 0.53 & 93.39 \\
\hline Neuroendocrinology & 3.22 & 0 & 0 & 0.71 & 1.05 & 95.02 \\
\hline J. Comp. Psychol. & 1.89 & 1.30 & 1.85 & 0 & 2.11 & 92.85 \\
\hline Endocrinology & 1.89 & 1.30 & 0 & 0 & 1.05 & 95.76 \\
\hline Behav. Brain Res. & 2.46 & 0.87 & 0 & 0 & 0 & 96.67 \\
\hline Aggress. Behav. & 2.65 & 0 & 0 & 0 & 0 & 97.35 \\
\hline Biol. Reprod. & 1.89 & 0.87 & 0 & 0.71 & 0.53 & 96 \\
\hline Anim. Behav. & 0.19 & 0.43 & 0 & 3.55 & 3.16 & 92.67 \\
\hline Brain Res. Bull. & 0.57 & 0 & 0 & 0 & 3.68 & 95.75 \\
\hline Other journals & 41.67 & 59.13 & 75.00 & 45.39 & 52.63 & \\
\hline
\end{tabular}


Table 4

Percentage of citations per behaviors for several journals

\begin{tabular}{|c|c|c|c|c|c|c|c|c|}
\hline Journal & $\begin{array}{l}\text { Sexual } \\
\text { behavior }\end{array}$ & $\begin{array}{l}\text { Aggressive } \\
\text { and emotional } \\
\text { responses }\end{array}$ & $\begin{array}{l}\text { Regulatory } \\
\text { behaviors }\end{array}$ & $\begin{array}{l}\text { Memory, } \\
\text { learning, and } \\
\text { conditioning }\end{array}$ & $\begin{array}{l}\text { Social } \\
\text { communication }\end{array}$ & $\begin{array}{l}\text { Sensation and } \\
\text { perception }\end{array}$ & Parental care & $\begin{array}{l}\text { Other } \\
\text { behavior }\end{array}$ \\
\hline Horm. Behav. & 12.67 & 9.49 & 12.94 & 13.61 & 17.81 & 19.23 & 20.97 & 0 \\
\hline Physiol. Behav. & 13.23 & 9.83 & 5.88 & 10.20 & 10.27 & 26.92 & 12.90 & 10.77 \\
\hline Brain Res. & 5.10 & 0.68 & 1.18 & 6.12 & 2.74 & 0 & 0 & 84.18 \\
\hline Gen. Comp. Endocrinol. & 2.46 & 5.42 & 3.53 & 0 & 2.05 & 0 & 4.84 & 81.7 \\
\hline Behav. Neurosci. & 1.51 & 2.03 & 0 & 7.48 & 3.42 & 0 & 8.06 & 77.5 \\
\hline Neurosci. Biobehav. Rev. & 3.21 & 1.36 & 2.35 & 1.36 & 1.37 & 0 & 6.45 & 83.9 \\
\hline Anim. Behav. & 0.19 & 5.08 & 2.35 & 0 & 5.48 & 26.92 & 0.81 & 59.17 \\
\hline J. Neuroendocrinol. & 4.73 & 0.68 & 1.18 & 0 & 2.74 & 0 & 0 & 90.67 \\
\hline Psychoneuroendocrinology & 1.70 & 2.03 & 2.35 & 2.04 & 2.05 & 0 & 0.81 & 89.02 \\
\hline Aggress. Behav. & 0.76 & 4.41 & 0 & 0 & 2.74 & 0 & 0 & 92.09 \\
\hline Behav. Brain Res. & 2.46 & 0.34 & 0 & 1.36 & 2.05 & 0 & 1.61 & 92.18 \\
\hline Endocrinology & 1.13 & 1.02 & 3.53 & 0 & 0.68 & 0 & 4.84 & 88.80 \\
\hline Brain Res. Bull. & 1.51 & 0 & 1.18 & 0.68 & 1.37 & 0 & 0 & 95.26 \\
\hline Neuroendocrinology & 1.32 & 0.68 & 0 & 0 & 0 & 0 & 1.61 & 96.39 \\
\hline J. Comp. Psychol. & 0.76 & 0.34 & 0 & 0 & 0.68 & 0 & 3.23 & 94.99 \\
\hline Biol. Reprod. & 1.13 & 0.34 & 1.18 & 0 & 0 & 0 & 0.81 & 96.54 \\
\hline Other journals & 46.12 & 56.27 & 62.35 & 57.14 & 44.52 & 26.92 & 33.06 & \\
\hline
\end{tabular}

and Serrano, 2002). In 1975, Beach described this field as an "emerging discipline" (Beach, 1975). At the beginning of the 1980s, Beach (1981) reported an approximate 20-fold increase in the research volume dedicated to the hormonal control of behavior in the years between 1955 and 1980 . He divided the history of this "emerging discipline" into three periods (predisciplinary, formative, and modern eras), which covered the space of time between 1849 , year of the publication of A.A. Berthold's experiments (Berthold, 1849), and 1981, when this historical revision was published. He emphasized the important role displayed by sexual behavior in rodents in this research field and indicated a reduction in this topic together with other important characteristics of evolution: an increase in the quantity of research; advances in correlational studies; explanation of mechanisms of hormonal action; adaptive values of hormonal control of behavior, and attenuation of disciplinary distinctions. Beach predicted the recognition of behavioral endocrinology as a mature discipline during the last quarter of the 20th century.

It is widely recognized by science historians and researchers that the main form of scientific expression is the journal. Findings relevant for behavioral endocrinology are being currently published in many different journals, although probably Hormones and Behavior continues to be the most representative of the field. Studying the evolution of this journal one is able to follow the development of this discipline and even to test, to a certain extent, the validity in the last 20 years of the tendencies detected by Beach (1981).

Gandelman (1984) reported that, due to both historical factors and certain practical considerations, reproductive behavior has been regarded as the dependent variable of choice for research in behavioral endocrinology. We have found a clear tendency in the last 14 years, which confirms the persistent decrease reported previously (Beach, 1981; Svare, 1988). Our results revealed that investigators who have published in Hormones and Behavior have shown a progressive diversification in the study of hormonal effects on behavior, with a progressive tendency to study a wider variety of behaviors. It is interesting to note the increase found in the number of articles dedicated to aggressive and emotional responses. Although this subject has an important tradition (Gandelman, 1984) in behavioral endocrinology, the most important change is related to the increasing interest in emotions developed in the last years. This field, which is experiencing a very important, rapid expansion, is now considered to be a specific, new emerging discipline named affective neuroscience (Davidson and Sutton, 1995), where studying hormonal influences on behavior and psychological processes plays a central role.

Furthermore, it is important to take into account the increasing number of reports with more than one behavior, which indicates that authors are interested in the interrelation between behaviors and their hormonal basis. Many of the combinations detected are based on the current interests in the mechanisms of hormonal action. Advances at the molecular level are guaranteed in the next few years; however, some warnings have been formulated with regard to this progress. For instance, Brush and Levine (1989, p. vi) remind us that Beach had "expressed concern that the glamour of molecular biology would divert attention from the fundamental question of what regulates behavior." At the basic level, several pieces of data suggest that the advances in molecular and cellular biology could breach the disciplinary barriers originated mostly by previous methodologies that divided the scientific field into different branches, such as endocrinology (Wilson, 2000). Survival as a distinct field depends, in the words of Wilson, on the recognition of 
the fact that many of the unresolved issues in the field involve whole animal physiology. In this sense, since behavior corresponds to the whole animal, behavioral endocrinology should have its continuity guaranteed.

Furthermore, the interest in numerous species is a clear characteristic of Hormones and Behavior, in contrast with the contents of other journals. This point is closely related to the importance given to adaptive values of hormonal control of behavior within behavioral endocrinology and field studies that are concerned with ecological validity. Despite all this, the number of articles dedicated to Rodents is still greater than those corresponding to the rest. A tendency of a slight, but persistent decrease in works on Rodents and an increased study of other species, especially Humans, has been confirmed in our study. A possible explanation can be that researchers are betting on the external validity, in spite of the difficulties in human experimentation. Technical improvements, such as salivary hormonal determinations, have opened up important possibilities in studying reciprocal influences between hormones and behavior in Humans, although a predominant number of studies have maintained a correlational approach. Several topics are being studied, and there is no clear dominant subject in this subarea.

In addition, the publication trends described have been complemented in this study, for the first time, with an analysis of the visibility of the articles during the period studied. Results clearly show that research in Humans reached the highest visibility index, pointing out that during the last decade not only did research increase, but the results obtained had a comparatively higher impact than those obtained from other species. Nonrodent/Nonhuman Mammals also reached a rather high visibility, while Rodents and nonmammal species attracted less attention. Concerning the behavioral patterns studied, Sexual Behavior presented a lower but stable visibility index. Aggressive and Emotional Responses showed a higher level of visibility, although in later years it presented a slightly decreasing trend. Interestingly, Memory, Learning, and Conditioning showed a high visibility index during the later years of the period studied. The articles in this category included research on spatial recognition and memory in animals and two studies on Humans regarding Alzheimer's disease and positron emission tomographic imaging.

Finally, the analysis of the journals that cite the articles published in Hormones and Behavior shows that Physiology and Behavior is the one that pays the most attention to them, apart from Hormones and Behavior itself. Among the 16 journals that produce about $50 \%$ of the citations, we find different interests, some focused on behavior, while others pay particular attention to neural substrates and mechanisms or adopt a comparative approach. If we consider journals that show a percentage of citations higher than $5 \%$, this number being arbitrarily selected, we can obtain a small view of which journals are more predisposed to specific aspects of research in behavioral endocrinology.

In summary, the predicted increase in the quantity of research in behavioral endocrinology has a clear exponent in the amplification of volumes and numbers published each year in Hormones and Behavior. Sexual behavior in rodents is still a promising field for behavioral endocrinologists, although the study of other behaviors, and especially of the interrelationships between them, is attracting more interest. Researchers are extending their topics and complementing their studies with more than a sole behavior, whereas the recognition of adaptive values of hormonal control of behavior and the interest in the explanation of mechanisms of hormonal action are maintained. Finally, the attenuation of disciplinary distinctions, another of the trends emphasized by Beach, is clearly expressed in the aims of the journal and of the society for which it is the organ of expression. Furthermore, the visibility trends shown by the articles published also suggest that research on Humans concerning Aggressive and Emotional Responses, as well as Memory, Learning, and Conditioning, reach the highest visibility indexes during the period studied. In any case, Beach's prediction about the recognition of behavioral endocrinology as a mature discipline for the last quarter of the 20th century has been fulfilled, and recent developments are broadening the issues, species, and behavioral patterns studied.

\section{References}

Beach, F.A., 1950. The snark was a boojum. Am. Psychol. 5, 115-124.

Beach, F.A., 1975. Behavioral endocrinology: an emerging discipline. Am. Scient. 63, 178-187.

Beach, F.A., 1981. Historical origins of modern research on hormones and behavior. Horm. Behav. 15, 325-376.

Berthold, A.A., 1849. Transplantation der hoden. Arch. Anat. Physiol. Wessensch. Med. 16, 42-49.

Brush, F.R., Levine, S., 1989. Psychoendocrinology. Academic Press, San Diego.

Davidson, R.J., Sutton, S.K., 1995. Affective neuroscience: the emergence of a discipline. Curr. Opin. Neurobiol. 5, 221-224.

Gandelman, R., 1984. Relative contributions of aggression and reproduction to behavioral endocrinology. Aggress. Behav. 10, 123-133.

Salvador, A, Serrano, M.A., 2002. Perspectiva histórica y tendencias de investigación de la Psicoendocrinologia. Revista de Psicologia General y Aplicada 55, 285-311.

Svare, B., 1988. Some trends in the responses studied and the species employed by behavioral endocrinologists. Horm. Behav. 22, 139-142.

Wilson, J.D., 2000. Endocrinology: survival as a discipline in the 21st century? Annu. Rev. Physiol. 62, 947-950. 